\title{
Electronic and optical properties of nickel-doped ceria: A computational modelling study
}

\begin{abstract}
Hussein A. Miran ${ }^{1 *}$, Zainab N. Jaf ${ }^{1}$
Cerium oxide $\left(\mathrm{CeO}_{2}\right)$, or ceria, has gained increasing interest owing to its excellent catalytic applications. Under the framework of density functional theory (DFT), this contribution demonstrates the effect that introducing the element nickel $(\mathrm{Ni})$ into the ceria lattice has on its electronic, structural, and optical characteristics. Electronic density of states (DOSs) analysis shows that $\mathrm{Ni}$ integration leads to a shrinkage of Ce $4 f$ states and improvement of $\mathrm{Ni} 3 d$ states in the bottom of the conduction band. Furthermore, the calculated optical absorption spectra of an Ni-doped $\mathrm{CeO}_{2}$ system shifts towards longer visible light and infrared regions. Results indicate that Ni-doping a $\mathrm{CeO}_{2}$ system would result in a decrease of the band gap. Finally, Mulliken's charge transfer of the $\mathrm{Ce}_{1-x} \mathrm{Ni}_{x} \mathrm{O}_{2}$ system exhibits an ionic bond between $\mathrm{Ce}$ or $\mathrm{Ni}$ and $\mathrm{O}$, and covalent bonds between $\mathrm{Ce}$ and $\mathrm{Ni}$ atoms. The analysis of absorption spectra demonstrates that Ni-doped $\mathrm{CeO}_{2}$ is a material with potential use in photocatalytic, photovoltaic, and solar panels.
\end{abstract}

\section{Introduction}

Cerium oxide (ceria or $\mathrm{CeO}_{2}$ ) based materials have generated extensive interest due to their exceptional electronic, optical, magnetic, and mechanical properties. Ceria is used in a broad array of applications such as catalysts $[1,2]$, photocatalysts, optoelectronics and opto-magnetic devices $[3,4]$. One of the features that renders ceria useful for catalysis is its ability to release or uptake oxygen from its lattice without substantial structural re-arrangement or the loss of its fluorite lattice $[5,6]$. In the fluorite structure, Ce atoms demonstrate a change in oxidation state from $\mathrm{Ce}^{4+}$ to $\mathrm{Ce}^{3+}$ and increase the tendency for redox [7]. Nickel-based compounds, on the other hand, are being revealed to have fun-

*hussein.a.j@ihcoedu.uobaghdad.edu.iq

1 Department of Physics, College of Education for Pure Sciences / Ibn-Al-Haitham, University of Baghdad, Baghdad, Iraq. damental and technological applications [8-10]. It has been reported that the introduction of dopants into ceria can facilitate band gap reduction, which in turn leads to the extension of light absorption into the visible range of electromagnetic radiation. Corma et al. [11] suggested that non-dye-sensitized solar cells with suitable dopant levels may deliver a new group of effective solar cells that, without photosensitization, have photovoltaic behaviour in the visible range. Qi-Ye proposed that, while pure $\mathrm{CeO}_{2}$ exhibits a trivial dielectric constant of 4 , inserting a small amount of Fe (0.9 at. \%) promotes densification and results in a larger dielectric constant of 23. Furthermore, the absorption coefficient of Fe-doped $\mathrm{CeO}_{2}$ at frequencies extending from 0.2 to $1.8 \mathrm{THz}$ is less than $0.35 \mathrm{~cm}^{-1}$, suggesting that Fe-doped $\mathrm{CeO}_{2}$ is a probable terahertz $(\mathrm{THz})$ optical substance [12]. Moreover, Xia et al. [13] have fabricated Mn-modified $\mathrm{CeO}_{2}$ nanorods and reported that the peak of the absorption spectrum of $\mathrm{CeO}_{2}$ shifts from ultraviolet into the region of visible light after Mn insertion. Likewise, photolu- 
minescence spectra analysis of Ni-doped $\mathrm{CeO}_{2}$ films demonstrates that oxygen vacancies are formed upon Ni-doping of $\mathrm{CeO}_{2}$. The shift in the UV peak indicates that Ni-doping can notably tailor the electronic structure and band gap of $\mathrm{CeO}_{2}$. Tiwari et al. [14] reported the synthesis of $\mathrm{Ce}_{1-x} \mathrm{Ni}_{x} \mathrm{O}_{2}$ $\left(\begin{array}{lll}0 & \mathrm{x} & 0.1\end{array}\right)$ nanopowders. UV-visible analysis suggests a reduction of band gap upon incorporation of Ni atoms into the host lattice. They attributed the decrease in band gap to the augmented disorder caused by defect formations between valance and conduction bands. Another study reported the impact of $\mathrm{Mg}$ inclusion on optical performance of $\mathrm{CeO}_{2}$ nanowires. They concluded from the absorption spectra that band gap energy is minimized to $3.00 \mathrm{eV}$ when incorporating $\mathrm{Mg}$ ions [15]. Fe-doped $\mathrm{CeO}_{2}$ enhanced photocatalytic activity towards the degradation of Methyl Orange (MO) [16]. The inclusion of $\mathrm{Fe}$ and $\mathrm{Ni}$ ions into the crystal lattice of $\mathrm{CeO}_{2}$ nanoparticles significantly reduces the dielectric constant value of the pure $\mathrm{CeO}_{2}$ [17]. Literature regarding density functional theory (DFT) has revealed that inclusion of $\mathrm{Ni}$ into the $\mathrm{CeO}_{2}$ lattice would improve the catalytic and optical properties of the resulting system [18]. Likewise, we have theoretically confirmed that Titanium (Ti) doped ceria promotes a band gap reduction which in turn leads the modified system to be useful in optical and catalytic applications [19]. To this end, and motivated by the above-mentioned literature, this contribution demonstrates the theoretical prospect of Ni-substituted $\mathrm{CeO}_{2}$, aiming to gain insight into the electronic, structural, and optical properties of the adapted configurations.

\section{Methodology}

The computational modeling in this investigation was performed using the Cambridge Serial Total Energy Package (CASTEP) under the frame of density functional theory (DFT) [20]. The bare DFT was reported to undervalue the energy of the electronic band gap because of the robust Coulomb interaction between the electrons in the Ce $4 f$ state [21]. Therefore, the Hubbard factor (U) has been added to the DFT functional (GGA) in the form of $(\mathrm{GGA}+\mathrm{U})$, by which all the simulated findings were computed [22]. The DFT+U approach has previously been utilized to investigate thermo-

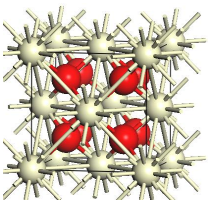

(a)

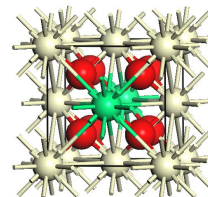

(b)

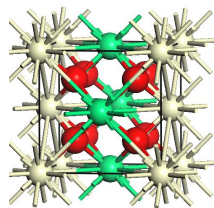

(c)

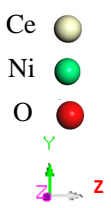

Figure 1: The optimized unit cell structures of $\mathrm{Ce}_{1-x} \mathrm{Ni}_{x} \mathrm{O}_{2}$ systems as plotted by VESTA visualization software at (a) $x=0$, (b) $x=0.25$, (c) $x=0.50$. White spheres represent Ce atoms; light green spheres denote $\mathrm{Ni}$ atoms, and $\mathrm{O}$ atoms are indicated by red spheres.

dynamic stability of $\mathrm{CoCu}_{2} \mathrm{O}_{3}$ surfaces [23]. Additionally, according to the suggested values of the default CASTEP settings, the U values were fixed at $6.0 \mathrm{eV}$ for $\mathrm{Ce}$ and $2.5 \mathrm{eV}$ for Ni. Ultrasoft pseudopotentials were utilized to describe the interaction between electrons and ions in reciprocal space with valence electron arrangements of $2 s^{2} 2 p^{4}$ for $\mathrm{O}, 3 d^{8} 4 s^{2}$ for $\mathrm{Ni}$, and $4 f^{1} 5 s^{2} 5 p^{6} 5 d^{1} 6 s^{2}$ for Ce. To set the Ni-doped concentrations, the substitution systems were built at $x=0.25$, and 0.50 , suggesting that at $x=0.25$, only one Ce atom has been replaced by $\mathrm{Ni}$, whereas for $x=0.50$, two vacant $\mathrm{Ce}$ atoms are occupied by $\mathrm{Ni}$. In a similar approach, the $\mathrm{Ce}_{1-x} \mathrm{Ni}_{x} \mathrm{O}_{2}$ systems correspond to $\mathrm{Ni}$ concentrations of $x=0.25$ and 0.50 , as depicted in Fig. 1. In order to minimize the total energy of $\mathrm{Ce}_{1-x} \mathrm{Ni}_{x} \mathrm{O}_{2}$ structures, a cut off energy of 300 $\mathrm{eV}$ was set along with a Monkhorst-Pack grid of $3 \times 2 \times 2 k$-points in the Brillouin zone. The energy convergence tolerance was fixed at $5.0 \times 10^{-6}$ $\mathrm{eV} /$ atom. For the geometry optimization process of the investigated structures, the maximum displacement tolerances, maximum stress, maximum force and energy change were set at $0.001 \AA, 0.05$ GPa, $0.03 \mathrm{eV} / \AA$ and $1 \times 10^{-6} \mathrm{eV} /$ atom, respectively. Electronic properties such as total and partial density of states and the Mulliken bond population, as well as optical properties, were directly computed by CASTEP. Lastly, to reproduce the exact electronic band gap energy of $\mathrm{CeO}_{2}$, a scissor operator of $1 \mathrm{eV}$ was applied and employed for all the following optical calculations. 
PAPers in Physics, vol. 14, ART. 140002 (2022) / Hussein A. Miran et al.

Table 1: The calculated lattice constants $(\AA)$, band gap energy $(\mathrm{eV})$, and charge distribution (e) for bare and Ni-modified $\mathrm{CeO}_{2}$ structures.

\begin{tabular}{|c|c|c|c|c|c|c|}
\hline \multirow[t]{2}{*}{ Geometry } & \multirow[t]{2}{*}{$\begin{array}{c}\text { Lattice parameter } \\
(\AA)\end{array}$} & \multirow[t]{2}{*}{$\begin{array}{l}\text { Formation Energy } \\
(\mathrm{eV})\end{array}$} & \multirow[t]{2}{*}{$\begin{array}{c}\text { Band gap energy } \\
(\mathrm{eV})\end{array}$} & \multicolumn{3}{|c|}{$\begin{array}{l}\text { Charge distribution } \\
\text { (e) }\end{array}$} \\
\hline & & & & $\mathrm{Ce}$ & $\mathrm{Ni}$ & $\mathrm{O}$ \\
\hline $\mathrm{CeO}_{2}$ & $a=5.46$ & - & 3.19 & 1.30 & - & -0.65 \\
\hline $\mathrm{Ce}_{0.75} \mathrm{Ni}_{0.25} \mathrm{O}_{2}$ & $a=5.36$ & -7.94 & 1.75 & 1.34 & 0.27 & -0.59 \\
\hline $\mathrm{Ce}_{0.50} \mathrm{Ni}_{0.50} \mathrm{O}_{2}$ & $a=5.22$ & -7.10 & 1.55 & 1.43 & 0.71 & -0.53 \\
\hline
\end{tabular}

\section{Results and discussion}

\section{i. Geometrical relaxation}

The relaxed configurations of bare and $\mathrm{Ni}$-doped $\mathrm{CeO}_{2}$ are displayed in Fig. 1. Typically, $\mathrm{CeO}_{2}$ adopts a cubic fluorite-type structure with a space group of (Fm-3m). The number of formula units in the unit cell corresponds to four (i.e. 4 cerium atoms and 8 oxygen atoms). The calculated lattice constants confirmed the experimental amount of a $=5.410 \AA$ [24], and these constants, along with the Mulliken population findings of the relaxed structures, are presented in Table 1 . The atomic radius of $\mathrm{Ce}$ is larger than the atomic radius of $\mathrm{Ni}$, which correspond to $2.7 \AA$ and $1.62 \AA$, respectively. Therefore, a reduction in the lattice constants can be observed when $\mathrm{Ni}$ contents increase, suggesting a lattice alteration by the insertiion of $\mathrm{Ni}$ ions. To assess the stability of the chosen doped matrix along with the difficulty of Ni-doping such a system, the doping formation energy $\left(E_{f}\right)$ has been computed for the systems via the following relationship [25]:

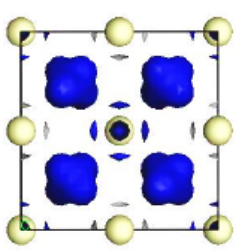

(a)

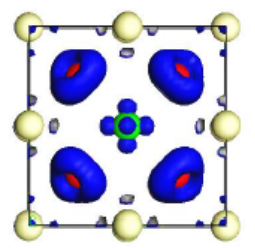

(b)

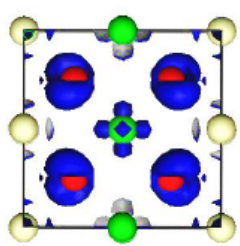

(c)
Figure 2: The calculated electron density difference for the studied systems. (a), (b), (c) corresponding to $\mathrm{CeO}_{2}, \mathrm{Ce}_{1-x} \mathrm{Ni}_{x} \mathrm{O}_{2}(x=0.25), \mathrm{Ce}_{1-x} \mathrm{Ni}_{x} \mathrm{O}_{2}$ $(x=0.50)$, respectively.

$$
E_{f_{\mathrm{Ce}_{k} \mathrm{Ni}_{l} \mathrm{O} m}}=\frac{E_{\mathrm{Ce}_{k} \mathrm{Ni}_{l} \mathrm{O}_{m}}-k E_{\mathrm{Ce}}-l E_{\mathrm{Ni}}-m E_{\mathrm{O}}}{k+l+m},
$$

wherein the parameters $k, l$ and $m$, refer to the molar fractions of elements $\mathrm{Ce}, \mathrm{Ni}$, and $\mathrm{O}$ in the alloyed systems.

The negative values of doping formation energy depicted in Table 1 indicate that the selected structures are stable and some amount of energy is released with the introduction of $\mathrm{Ni}$ atoms into the host system. Regarding the comparison between the current system and the system studied in Ref. [19], both systems are stable since the formation energies reveal negative values. Table 1 reports Mulliken's charge populations of $\mathrm{Ce}, \mathrm{O}$ and $\mathrm{Ni}$ atoms in the $\mathrm{Ce}_{1-x} \mathrm{Ni}_{x} \mathrm{O}_{2}$ system. As the table shows, $\mathrm{Ce}$ and $\mathrm{Ni}$ atoms in the studied structures tend toward positive charges whereas $\mathrm{O}$ atoms are linked to negative charges.

The simulation results of Mulliken's charge values also indicate a covalent behaviour for the $\mathrm{Ni}$ Ce bond in the designated structures that comprise $\mathrm{Ni}$ and $\mathrm{Ce}$ atoms, and ionic properties for $\mathrm{Ni}-\mathrm{O}$

Table 2: The interatomic distances $(\AA)$ and angles $\left(^{\circ}\right)$ between the selected atoms of the studied systems.

\begin{tabular}{lcccc}
\hline \hline \multirow{2}{*}{ Geometry } & \multicolumn{2}{c}{$\begin{array}{c}\text { Interatomic } \\
\text { distances }(\AA)\end{array}$} & \multicolumn{2}{c}{$\begin{array}{c}\text { Angles } \\
\left({ }^{\circ}\right)\end{array}$} \\
\hline \multirow{2}{*}{$\mathrm{CeO}_{2}$} & $\mathrm{Ce}-\mathrm{O}$ & 2.36 & O-Ce-O & 70.52 \\
& $\mathrm{O}-\mathrm{O}$ & 2.73 & & \\
\hline \multirow{2}{*}{$\mathrm{Ce}_{0.75} \mathrm{Ni}_{0.25} \mathrm{O}_{2}$} & $\mathrm{Ni}-\mathrm{O}$ & 2.26 & O-Ni-O & 69.97 \\
& $\mathrm{Ce}-\mathrm{O}$ & 2.31 & O-Ce-O & 69.83 \\
& $\mathrm{O}-\mathrm{O}$ & 2.61 & Ni-O-Ce & 110.88 \\
\hline \multirow{2}{*}{$\mathrm{Ce}_{0.50} \mathrm{Ni}_{0.50} \mathrm{O}_{2}$} & $\mathrm{Ni}-\mathrm{O}$ & 2.19 & O-Ni-O & 64.98 \\
& $\mathrm{Ce}-\mathrm{O}$ & 2.32 & O-Ce-O & 68.42 \\
& $\mathrm{O}-\mathrm{O}$ & 2.59 & Ni-O-Ce & 109.01 \\
\hline \hline
\end{tabular}


Papers in Physics, vol. 14, ART. 140002 (2022) / Hussein A. Miran et al.
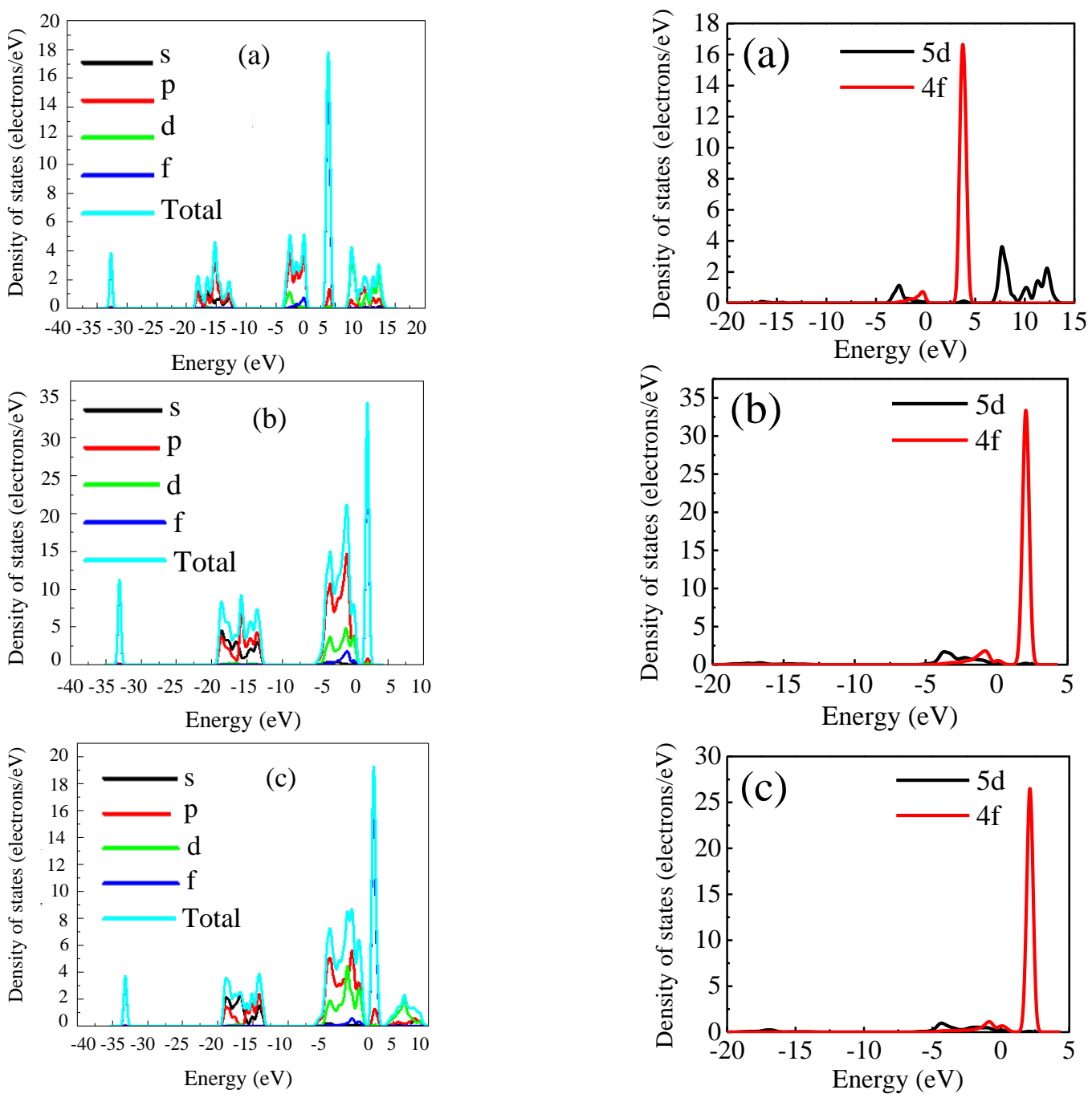

Figure 3: The total density of states (TDOSs) and partial density of states (PDOSs) of $\mathrm{Ce}_{1-x} \mathrm{Ni}_{x} \mathrm{O}_{2}$ unit cell versus the energy of electrmagnetic wave at (a) $x=0$, (b) $x=0.25$, (c) $x=0.50$.

and $\mathrm{Ce}-\mathrm{O}$ bonds. Furthermore, the findings show that Ce atoms lose more electrons once $\mathrm{Ni}$ is implanted into the host lattice, whereas the increase in $\mathrm{O}$ atoms' electrons is approximately constant as $\mathrm{Ni}$ contents increase [26]. Figure 2 displays the distribution of the charge density, and the blue colour around the $\mathrm{O}$ atoms demonstrates the electron density gain resulted from inserting $\mathrm{Ni}$ atoms.

Furthermore, Table 2 demonstrates the calculated interatomic bonds and angles between select

Figure 4: $5 d$ and $4 f$ orbitals of Ce atom in $\mathrm{Ce}_{1-x} \mathrm{Ni}_{x} \mathrm{O}_{2}$, (a) $x=0$, (b) $x=0.25$, (c) $x=0.50$.

atoms of the optimized structures. The findings indicate a reduction in the bonds and angles of the doped systems as compared to the host $\mathrm{CeO}_{2}$ lattice.

\section{ii. Electronic properties analysis}

The electronic properties of the $\mathrm{Ce}_{1-x} \mathrm{Ni}_{x} \mathrm{O}_{2}$ system can be investigated by studying the density of states (DOSs) of the relaxed geometries. Results of DOSs are plotted and shown in Fig. 3. $\mathrm{CeO}_{2}$ demonstrates non-metallic behaviour, indicating 
Papers in Physics, vol. 14, ART. 140002 (2022) / Hussein A. Miran et al.
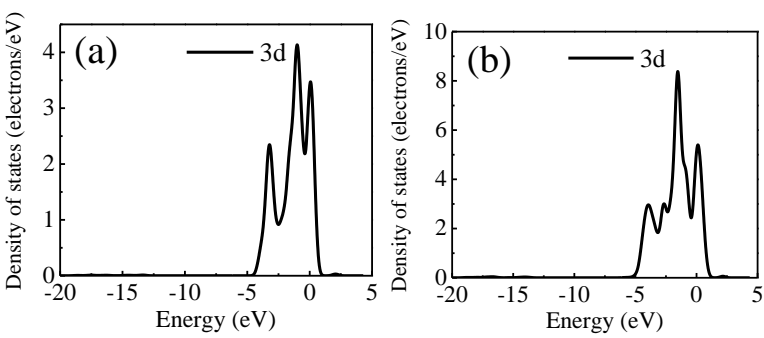

Figure 5: $3 d$ orbitals of $\mathrm{Ni}$ atom loadings in $\mathrm{Ce}_{1-x} \mathrm{Ni}_{x} \mathrm{O}_{2}$ system. (a) $x=0.25$, (b) $x=0.50$.

a semiconducting nature. The Fermi level is situated at zero energy in order to clearly identify the band gap energy. Regarding the bare $\mathrm{CeO}_{2}$ unit cell, the DOSs plotted correspond well with the results of previously published studies [27]. The uppermost valance band is extended from -3.7 to 0 $\mathrm{eV}$ (Fermi level), while the conduction band is located at $3.19 \mathrm{eV}$ above the Fermi level. This finding signifies the possibility of reproducing the experimentally assessed band gap energy of [28] 3.19 as portrayed in Fig. 3(a). Moreover, Ni-doped ceria at various contents $(0.25$ and 0.50$)$ involve high intensity states in the conduction and valence bands. On the other hand, band gap energy is minimized to $1.75 \mathrm{eV}$ and $1.55 \mathrm{eV}$ at $\mathrm{Ni}$ concentrations of 0.25

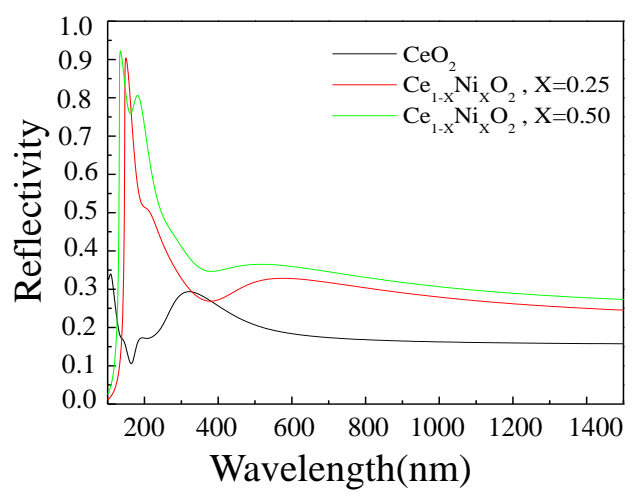

Figure 6: Reflectance spectra of pure $\mathrm{CeO}_{2}$ and Nidoped $\mathrm{CeO}_{2}$ configurations. As Fig. 6 shows, spectra representing $\mathrm{Ni}$-added $\mathrm{CeO}_{2}$ reveal high reflectivity values in the ultra-violet region when compared to the pure ceria reflectivity spectrum. Further, all the spectra demonstrate a moderate trend to reflect incident photons within the visible range [29].

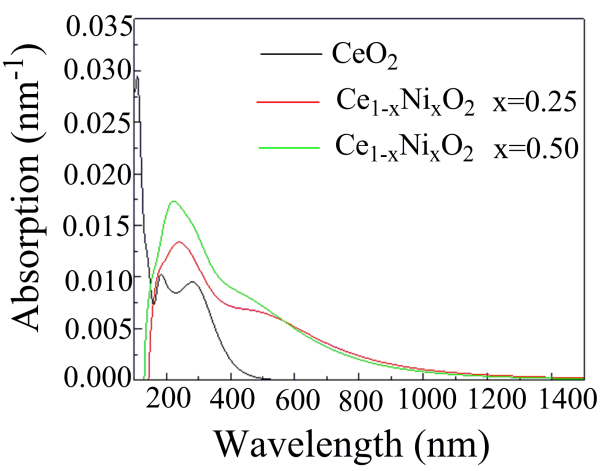

Figure 7: The calculated absorption spectra for bare and $\mathrm{Ni}$-doped $\mathrm{CeO}_{2}$ configurations.

and 0.50 , correspondingly, thus demonstrating that $\mathrm{Ni}$ integration into ceria would minimize the band gap energy. Figure 4 shows DOS plots of $5 d$ and $4 f$ states of Ce atom in pure and doped $\mathrm{Ce}_{1-x} \mathrm{Ni}_{x} \mathrm{O}_{2}$. As seen from the figure, $4 f$ states in the conduction band shift toward the Fermi level as the $\mathrm{Ni}$ concentration increases, resulting in a reduction of the electronic band gap.

Furthermore, comparing the $\mathrm{Ni} 3 d$ states in the $\mathrm{Ce}_{1-x} \mathrm{Ni}_{x} \mathrm{O}_{2}(x=0.25)$ with $(x=0.50)$ structures (depicted in Fig.5), it is observed that the Ni $3 d$ states are positioned at the same energy level, signifying that the Ni $3 d$ states would improve with rising $\mathrm{Ni}$ contents. Additionally, further reduction in the band gap energy with the introduction of $\mathrm{Ni}$ can be possibly ascribed to the accumulation of $\mathrm{Ni}$ $3 d$ states in the conduction band, leading to improved photocatalytic and optical performance of $\mathrm{Ce}_{1-x} \mathrm{Ni}_{x} \mathrm{O}_{2}$.

\section{iii. Optical properties}

The reflectivity of pure and Ni-doped $\mathrm{CeO}_{2}$ in terms of wavelength is shown in Fig. 6. As demonstrated, spectra represented by $\mathrm{Ni}$-added $\mathrm{CeO}_{2}$ reveal high reflectivity values in the ultra-violet region when compared to the reflectivity spectrum of pure ceria. Furthermore, all the spectra demonstrate a moderate trend to reflect incident photons within the visible range [29].

Absorption coefficients specify how far light of a certain energy or wavelength is able to enter a substance before absorption. The absorption spectra of the studied structures are shown in Fig. 7 
PAPers in Physics, vol. 14, ART. 140002 (2022) / Hussein A. Miran et al.

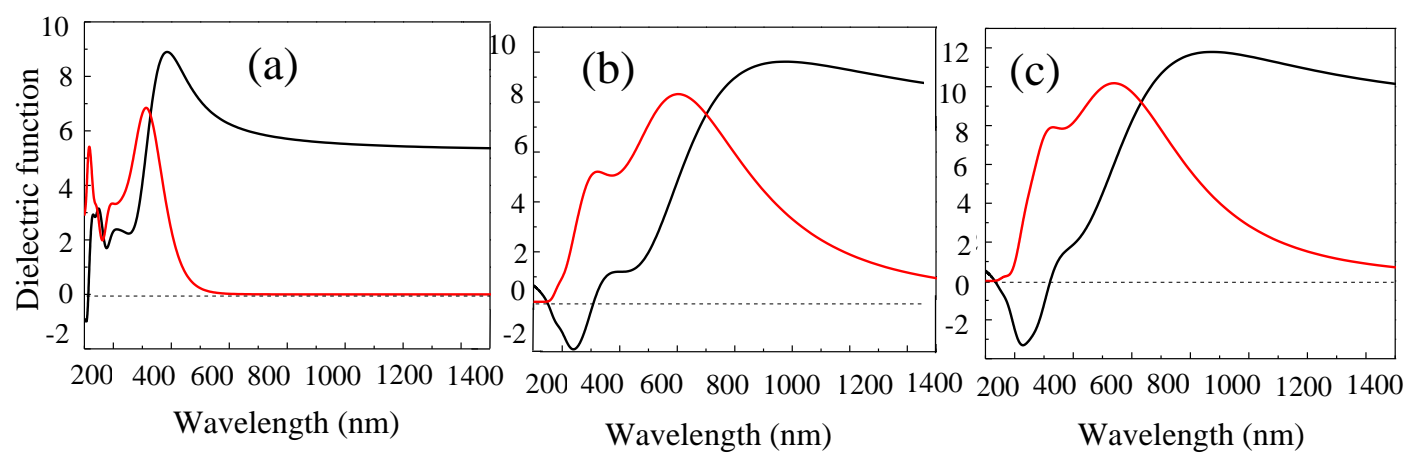

Figure 8: The real and imaginary components of dielectric function of $\mathrm{Ce}_{1-x} \mathrm{Ni}_{x} \mathrm{O}_{2}$ at (a) $x=0$; (b) $x=0.25$; (c) $x=0.50$. Black and red curves represent the real and imaginary parts, respectively.

and demonstrate a semiconductive character because the spectra originate at non-zero values of wavelength.

It is well known that the dielectric function is an important factor related to the absorption and polarization properties of materials. The examined dielectric constant of undoped and Ni-doped $\mathrm{CeO}_{2}$ are depicted in Fig. 8. The non-zero values of the imaginary component of the dielectric constant indicate the process of absorption in that energy region.

\section{Conclusions}

The current study demonstrates the influence of $\mathrm{Ni}$ addition on the electronic, structural and optical properties of $\mathrm{CeO}_{2}$. The attained outcomes recommend that addition of $\mathrm{Ni}$ into ceria would reduce the band gap to $1.75 \mathrm{eV}$ and $1.55 \mathrm{eV}$ at 0.25 and 0.50 , respectively. Moreover, Ni-doping introduces $3 d$ states in the conduction band of $\mathrm{CeO}_{2}$. The $3 d$ states have a significant effect on dropping the band gap energy. Furthermore, the absorption spectra of $\mathrm{CeO}_{2}$ is shifted from ultraviolet towards the visible ranges after Ni incorporation. This implies that optical absorption is elongated to a longer wavelength region. Mulliken's charge distribution displayed an ionic behaviour for $\mathrm{Ce}-\mathrm{O}$ and $\mathrm{Ni}-\mathrm{O}$ bonds, whereas $\mathrm{Ce}-\mathrm{Ni}$ bonds exhibited a covalent behaviour. Results from this study demonstrate that Ni-doped $\mathrm{CeO}_{2}$ is a potential candidate in photocatalytic and optical applications.
[1] C Riley, A De La Riva, et al. , Synthesis of nickel-doped ceria catalysts for selective acetylene hydrogenation, ChemCatChem 11, 1526 (2019).

[2] H A Miran, M Altarawneh, Z T Jiang, H Oskierski, M Almatarneh, B Z Dlugogorski, Decomposition of selected chlorinated volatile organic compounds by ceria $\left(\mathrm{CeO}_{2}\right)$, Catal. Sci. Technol. 7, 3902 (2017).

[3] Z G Yan, C H Yan, Controlled synthesis of rare earth nanostructures, J. Mater. Chem. 18, 5046 (2008).

[4] K R B Singh, V Nayak, T Sarkar, R P Singh, Cerium oxide nanoparticles: Properties, biosynthesis and biomedical application, RSC Adv. 10, 27194 (2020).

[5] H A Miran, Z N Jaf, M Altarawneh, Z-T Jiang, An insight into geometries and catalytic applications of $\mathrm{CeO}_{2}$ from a DFT outlook, Molecules 26, 6485 (2021).

[6] T Naganuma, E Traversa, Stability of the Ce3+ valence state in cerium oxide nanoparticle layers, Nanoscale 4, 4950 (2012).

[7] H A Miran, M Altarawneh, et al., Thermomechanical properties of cubic lanthanide oxides, Thin Solid Films 653, 37 (2018). 
PAPers in Physics, vol. 14, ART. 140002 (2022) / Hussein A. Miran et al.

[8] R Paulose, R Mohan, V Parihar, Nanostructured nickel oxide and its electrochemical behaviour A brief review, Nano-Structures \& Nano-Objects 11, 102 (2017).

[9] M F Altaee, L A Yaaqoob, Z K Kamona, Evaluation of the biological activity of nickel oxide nanoparticles as antibacterial and anticancer agents, Iraqi J. Sci. 61, 2888 (2020).

[10] A S Mohammed, I M Ibrahim, A Ramizy, Energy band diagram of $\mathrm{NiO}: \mathrm{Lu}_{2} \mathrm{O}_{3} / n$-Si heterojunction, Iraqi J. Sci. 59, 287 (2018).

[11] A Corma, P Atienzar, H García, J Y ChaneChing, Hierarchically mesostructured doped $\mathrm{CeO}_{2}$ with potential for solar-cell use, Nat. Mater. 3, 394 (2004).

[12] Q Y Wen, H W Zhang, Q H Yang, S Li, D G $\mathrm{Xu}, \mathrm{J}$ Q Yao, $\mathrm{Fe}$-Doped polycrystalline $\mathrm{CeO}_{2}$ as terahertz optical material, Chinese Phys. Lett. 26, 047803 (2009).

[13] C Xia, C Hu, P Chen, B Wan, X He, Y Tian, Magnetic properties and photoabsorption of the $\mathrm{Mn}$-doped $\mathrm{CeO}_{2}$ nanorods, Mater. Res. Bull. 45, 794 (2010).

[14] S Tiwari, G Rathore, et al., Oxygen and cerium defects mediated changes in structural, optical and photoluminescence properties of $\mathrm{Ni}$ substituted $\mathrm{CeO}_{2}$, J. Alloys Compd. 782, 689 (2019).

[15] X Ma, P Lu, P Wu, Structural, optical and magnetic properties of $\mathrm{CeO}_{2}$ nanowires with nonmagnetic Mg2+ doping, J. Alloys Compd. 734, 22 (2018).

[16] D Channei, B Inceesungvorn, N Wetchakun, S Ukritnukun, A Nattestad, J Chen, S Phanichphant, Photocatalytic degradation of methyl orange by $\mathrm{CeO}_{2}$ and $\mathrm{Fe}$-doped $\mathrm{CeO}_{2}$ films under visible light irradiation Sci. Rep. 4, 1 (2014).

[17] R Zamiri, S A Salehizadeh, H A Ahangar, M Shabani, A Rebelo, J M F Ferreira, Dielectric and optical properties of $\mathrm{Ni}$ - and $\mathrm{Fe}$ doped $\mathrm{CeO}_{2}$ nanoparticles, Appl. Phys. AMater. 125, 1 (2019).
[18] D Rajsfus, A Salcedo, B Milberg, B Irigoyen, Nickel deposition on ceria: A DFT $+U$ study, An. Asoc. Quim. Argent. 104, 44 (2017).

[19] H A Miran, Z N Jaf, I H Khaleel, A A Alkhafaji, Photocatalytic and optical performances of $\mathrm{CeO}_{2}$ by substitution of titanium, Phys. Chem. Res. 9, 553 (2021).

[20] M D Segall, P J D Lindan, M J Probert, C J Pickard, P J Hasnip, S J Clark, M C Payne, First-principles simulation: Ideas, illustrations and the CASTEP Code, J. Phys. Condens. Matter 14, 2717 (2002).

[21] A J Cohen, P Mori-Sánchez, W Yang, Insights into current limitations of density functional theory, Science 321, 792 (2008).

[22] H A Miran, M Altarawneh, Z N Jaf, M M Rahman, M H Almatarneh, Z T Jiang, Influence of the variation in the Hubbard parameter $(U)$ on activation energies of $\mathrm{CeO}_{2}$-catalysed reactions, Can. J. Phys. 98, 385 (2020).

[23] H Widjaja, H A Miran, M Altarawneh, I Oluwoye, H N Lim, N M Huang, Z T Jiang, B Z Dlugogorski, DFT $+U$ and ab initio atomistic thermodynamics approache for mixed transitional metallic oxides: A case study of $\mathrm{CoCu}_{2} \mathrm{O}_{3}$ surface terminations, Mater. Chem. Phys. 201, 241 (2017).

[24] Y Xue, D Tian, D Zhang, C Zeng, Y Fu, K $\mathrm{Li}, \mathrm{H}$ Wang, Y Tian, The mechanism of photocatalyst and the effects of co-doping $\mathrm{CeO}_{2}$ on refractive index and reflectivity from DFT calculation, Comput. Mater. Sci. 158, 197 (2019).

[25] W Bi, S Sun, S Bei, Y Jiang, Effect of alloying elements on the mechanical properties of $\mathrm{Mo}_{3} \mathrm{Si}$, Metals 11, 1 (2021).

[26] R Lawler, J Cho, H C Ham, H Ju, S W Lee, J Y Kim, J Il Choi, S S Jang, $\mathrm{CeO}_{2}(111)$ surface with oxygen vacancy for radical scavenging: A density functional theory approach, J. Phys. Chem. C 124, 20950 (2020).

[27] C Loschen, J Carrasco, K M Neyman, F Illas, First-principles $L D A+U$ and $G G A+U$ study of cerium oxides: Dependence on the effective U parameter, Phys. Rev. B 75, 035115 (2007). 
Papers in Physics, vol. 14, ART. 140002 (2022) / Hussein A. Miran et al.

[28] N V Skorodumova, R Ahuja, S I Simak, I A [29] Z N Jaf, Z T Jiang, H A Miran, M AlAbrikosov, B Johansson, B I Lundqvist, Electronic, bonding, and optical properties of $\mathrm{CeO}_{2}$ and $\mathrm{Ce}_{2} \mathrm{O}_{3}$ from first principles, Phys. Rev. B 64, 1151081 (2001).

\author{
tarawneh, Thermo-elastic and optical proper- \\ ties of molybdenum nitride, Can. J. Phys. 94, \\ 902 (2016).
}

